WSRC-TR- $-91-673$

DE93 003646

\title{
Environmental Test Program for Superconducting Materials and Devices $(U)$
}

H. Randolph and D. Verebelyi

Westinghouse Savannah River Company

Savannah River Site

Aiken, SC 29808

Prepared for the U. S. Department of energy under contract no. DE-AC09-89SR18035

MASTER 
This Page Intentionally Left Blank

-

- 


\title{
Environmental Test Program for Superconducting Materials and Devices
}

\author{
Investigators \\ Henry Randolph and Darren Verebelyi \\ Westinghouse Savannah River Company \\ Savannah River Site \\ Aiken, SC 29808
}

\section{Introduction}

The properties of $\mathrm{YBa}_{2} \mathrm{Cu}_{3} \mathrm{O}_{-x}$ superconducting tapes designed and fabricated into SAFIRE-type, encapsulated, grounding links by the Ceramic Engineering Department at Clemson University were investigated (NASA Contract No. NAG-1-1127). Testing at the Savannah River Site included gamma irradiation, vibration, magnetic field, and long-term evaluation. Irradiation and vibration did not change the physical or electrical properties of the tested samples. An applied magnetic field of 1000 Gauss increased the superconduction resistance and invoked semiconduictor electrical properties of some samples. The long-term testing began in January 1991 and resistance data showed no increases. No gaseous decomposition has been found.

\section{Radiation Test}

Eight samples were irradiated in a high level gamma well. These samples were received from Clemson with known resistance vs. temperature curves. Before irradiation the samples were videotaped. The full screen view equaled the width of the sample. The samples were then immersed in liquid nitrogen $\left(\mathrm{LN}_{2}\right)$ and exposed to ${ }^{17} \mathrm{Cs}$ for 126 total hours over a 10 day period. The main energy peak of the ${ }^{137} \mathrm{Cs}$ spectrum is at $661.66 \mathrm{keV}$. The calibrated exposure rate was $96.940 \mathrm{R} / \mathrm{hr}$. The equivalent gamma radiation dose in water is equal to $11,000 \mathrm{rad}$. The cross section for gamma absorption in superconducting material is greater. Therefore, the dose would be greater than $11,000 \mathrm{rad}$.

After irradiation these samples were videotaped again in the same manner as before exposure. The only physical change resulting from the treatment, was minor epoxy separation from the superconductor. This effect has been observed at Clemson on some samples during long periods of $\mathrm{LN}_{2}$ immersion. The samples were returned to Clemson for comparison resistance vs. temperature curves. These curves showed no change from the pre-test curves.

\section{Vibration Test}

Resistance vs. temperature curves on four unused samples were taken before vibration. Figures 1 and 2 are the original curves. All four samples had well defined transitions to the superconducting state and have an $80 \mathrm{~K}$ resistance of less than 5 milliohms. Using the first derivative of the resistance, data curves similar to Figure 3 show two distinct transitions. These two transitions are compiled in Table 1.

Samples 364, 365, 366, and 367 were then vibrated perpendicular to their face as shown in Figure 4. The Table 1

Original Critical Temperatures of the Four Vibration Test Samples

$\begin{array}{ccc}\text { Sample } & T_{c 1}(K) & T_{c}(K) \\ 364 & 94 & 89 \\ 365 & 94 & 90 \\ 366 & 92 & 87 \\ 367 & 93 & 90\end{array}$


Table 2

Vibration Test Variables (Total time: 18.5 minutes)

$\begin{array}{cccc}\begin{array}{c}\text { Time } \\ \text { (Seconds) }\end{array} & \begin{array}{c}\text { Frequency } \\ \text { (Hertz) }\end{array} & \begin{array}{c}\text { Acceleration } \\ (\mathrm{m} / \mathrm{s})\end{array} & \begin{array}{c}\text { Acceleration } \\ \text { (g's) }\end{array} \\ 750 & 15 & 70 & 7 \\ 350 & 16 & 50 & 5\end{array}$

samples were fixed to table supports at each end. All samples were in the same configuration when vibrated simultaneously. The elapsed time of vibration with the corresponding frequency and acceleration are shown in Table 2

After vibration, the samples had resistance vs. temperature curves taken again. These curves were compared to the previous curves and no major differences were found. Table 3 compares the original data to the post-vibration data. The post-vibration curves are shown in Figures 5 and 6. Overlays of the post-vibration curves on the original curves show the transition region in detail. Overlays are shown in Figures 7 and 8.

\section{Magnetic Field Test}

Resistance vs. temperature curves on four unused samples were first taken with no applied magnetic field. Figures 9 and 10 show the original curves of the four samples. Two of the samples were found to be poor, 362 and 363, and had superconducting resistances of several hundred milliohms.

Samples $360,361,362$, and 363 were then placed in a 1000 Gauss magnetic field and then cooled to $\mathrm{LN}_{2}$ temperature. The magnetic field was perpendicular to the face of the

Table 3 Original vs. Post-Vibration Critical Temperatures of the Four Test Samples

\begin{tabular}{lcccc} 
Sample & \multicolumn{2}{c}{$T_{\mathrm{Cl}_{1}}(\mathrm{~K})$} & \multicolumn{2}{c}{$\mathrm{Tc}_{\mathrm{c}}(\mathrm{K})$} \\
& Orig & Post & Orig & Post \\
& & & & \\
364 & 94 & 93 & 89 & 86 \\
365 & 94 & 94 & 90 & 90 \\
366 & 92 & 93 & 87 & 87 \\
367 & 93 & 93 & 90 & 90
\end{tabular}

sample and is shown in Figure 11. The excitation current used during a 4-wire ohm measurement was 10 milliamps.

The comparison data with and without the applied field is shown in Table 4. The first poor sample, 362, was slightly changed by the applied field. However, sample 363 became worse and uxhibited semiconductor properties. Sample 360 was unchanged in the field and had a critical temperature of 91K. Sample 361 was severely changed by the field and also exhibited a semiconductor-like increase in resistance during cooling. Figures 12 and 13 show the resistance vs. temperature curves to room temperature in an applied field. Figures 14 and 15 compare the curves at the transition with and without a field.

\section{Long-Term Test}

The long-term test monitored for decomposition byproducts and changes in resistance while maintaining low temperature $(77 \mathrm{~K})$ and high vacuum $\left(10^{-7}\right.$ torr). The equipment to perform measurements insluded a cryostat and a vacuum system consisting of stainless steel piping configured to accommodate two, 20-pin electronic signal feedthroughs, and ion pump, and a mass spectrometer head. Figures 16 and 17 show the vacuum system configuration. The cryostat is immersed in $\mathrm{LN}_{2}$ from a 50 liter dewar. $\mathrm{LN}_{2}$ is replenished to the 50 liter dewar by an interchangeable 160 liter dewar.

Continuous data acquisition by computer control compiled measurements of current, voltage, temperature, pressure, and partial pressure. Data were taken at 15 minute intervals and written into two text files along with a date and time stamp. Measurements were taken by a Hewlett Packard 3457 A Multimeter, Hewlett Packard Scanner, and a Dycor

Table 4 Zero vs. 1000 Gauss Comparison of the Four Samples

Sample $\quad \mathrm{Tc}(\mathrm{K}) \quad$ Resistance (milliohms)

- Zero Gauss 1K Gauss Zero Gauss IK Gauss

$\begin{array}{lllll}360 & 91 & 92 & <5 & <5 \\ 361 & 90 & 91 & <5 & 480^{*} \\ 362 & 93 & 93 & 110 & 103 \\ 363 & 93 & 93 & 440 & 1060^{*} \\ \text { * Exhibited Semiconductor Properties } & \end{array}$


Quadrupole Mass Spectrometer. The multimeter was certified and is NIST traceable.

Voltage and current measurements were written to disk and resistance was calculated from Ohm's law. Temperature was calculated from the resistance measurement of a calibrated ceramic Platinum Resistance Temperature Detector (RTD). Pressure was calculated from a voltage measurement on the ion pump controller. Partial pressures of 12 masses were normalized to the ion pump pressure in torr.

A current of 10 milliamps was applied to all eight samples for the first week, then the current was removed from four samples for the balance of the test. Samples were arranged in two groups of four as given in Table 5. The one-inch diameter cryostat holds the samples as shown in Figure 18. This orientation allows the temperature measurement to be an upper limit for the samples. The continuous current samples are at a lower temperature due to their position at the bottom of the cryostat. The thermal transfer of the tube produces a temperature gradient of approximately $7 \mathrm{~K}$ from the bottom of the cryostat to the RTD.

The long-term test portion of the program has been in progress for more than 6700 hours. Data were collected each minute during the initial cooling of the samples on 15 January 1991. Data from sample number 212 were omitted due to the failure to go superconducting after initial testing on 21 December 1990. The major abnormality found during the experiment was a negative potential from sample 204. This negative potential of several $\mu$ volts disappeared after

Table 5. The Two Groups of Samples in the LongTerm Test

$\begin{array}{lccc}\text { Group 1 } & \text { Sample } & \text { Type* } & \text { Constant Cument } \\ & 203 & \text { Tab } & \text { Yes } \\ & 204 & \text { Tab } & \text { Yes } \\ & 212 & \text { Pin } & \text { Yes } \\ \text { Group 2 } & 213 & \text { Pin } & \text { Yes } \\ & 232 & \text { Tab } & \text { No } \\ & 209 & \text { Tab } & \text { No } \\ \text { *ab = Silver foil tab connector } & \text { No } \\ \text { Pin = Gold plated pin connector } & \end{array}$

700 hours of testing. At this point the samples were at an abnormally high temperature of $110 \mathrm{~K}$. The normal state resistance of a sample is approximately one-ohm. There is a measured superconducting resistance for each sample due to the two-wire configuration of the samples. This superconducting resistance is several hundred $\mu$ ohms. Resistance data is the primary focus of the long-term experiment. The three samples to be evaluated are the constant current samples. These samples are 203, 204, and 214. Data segments 10 hours long were used for evaluation. These segments are chosen between dewar fills so no transients are present in the data. The temperature increase over a 10-hour segment was quite small in the beginning and has grown because of the better vacuum present in the system. The pressure is currently in the lower $10^{\circ}$ torr range. Data segments were taken at 366,2915 , and 6670 hours. Over this span of time the resistance of the samples showed no sign of increase. Figure 19 shown the sample's resistance for each data segment. Figure 20 is a bar graph of the average resistance for each sample and segment.

Physical degradation of the superconductors and encapsulant was evaluated through the use of gas analysis. The vacuum system is attached to a gas analyzer which can see the spectrum of asses up to $200 \mathrm{amu}$. Normal masses corresponding to water, nitrogen, carbon dioxide, and Hydrogen were seen. Other gases have not been continuously detected with partial pressures greater than $10^{-11}$ torr. At $10^{-11}$ torr, gas decomposition would not provide a measurable total mass loss from a sample.

\section{Conclusion}

Comprehensive testing was performed on 24 encapsulated superconductors provided by Clemson University under NASA Contract No. NAG-1-1127. Of the samples, three were found defective before testing. Twelve samples were gamma irradiated and vibrated with no permanent damage inflicted. A magnetic field was found to cause substantial interruption in the electrical properties of some samples. The primary effect was the induced semiconductor phases.

The long-term testing has not lead to the destruction of the samples investigated. The encapsulant has protected the superconductor from a high vacuum at $\mathrm{LN}_{2}$ temperature. Overall, the samples tested were durable physically and electrically and have withstood exposure to the adversities of a space environment. 
This Page Intentionally Left Blank 


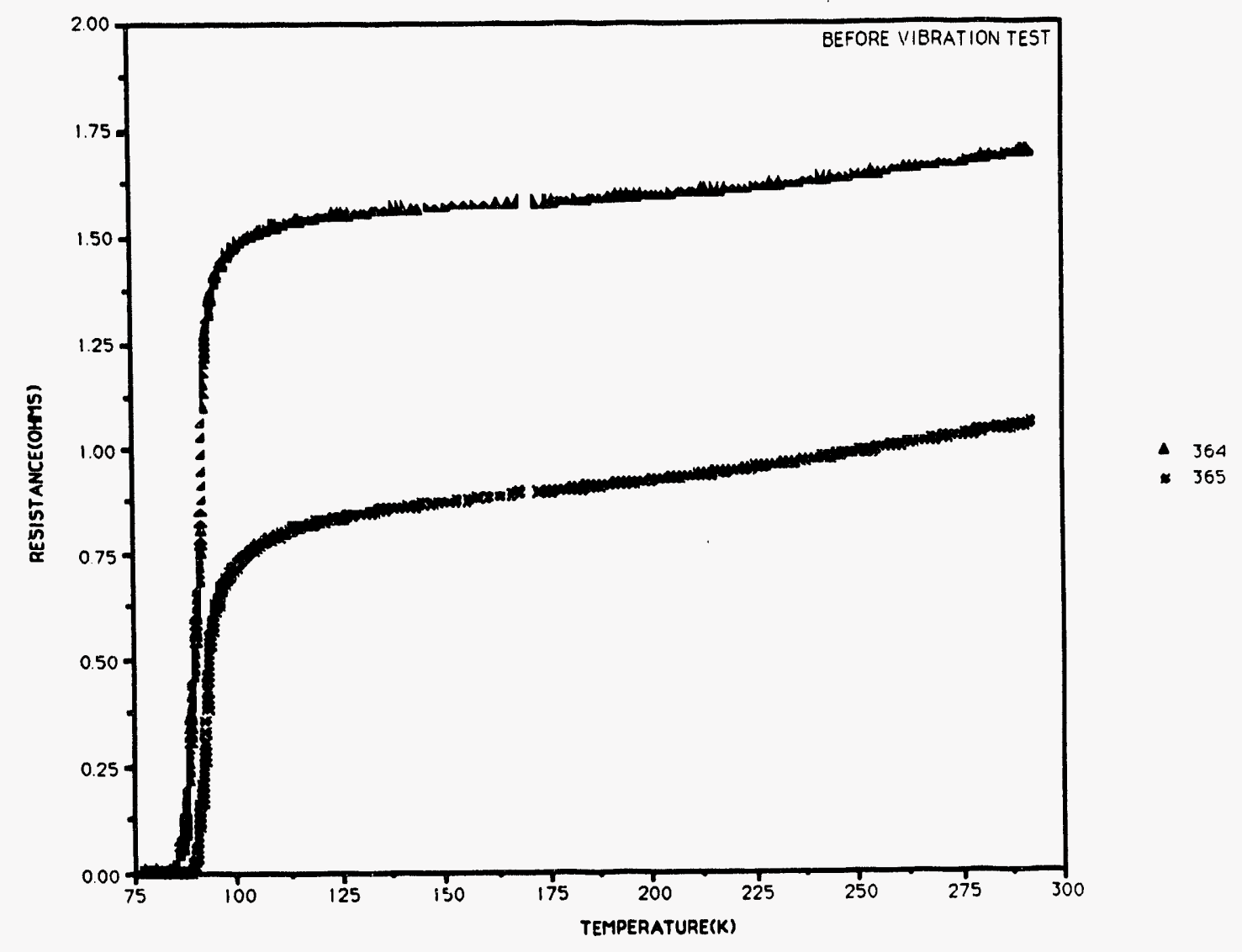

Figure 1. Sample 364 and 365 Resistance vs. Temperature Curves before Vibration 


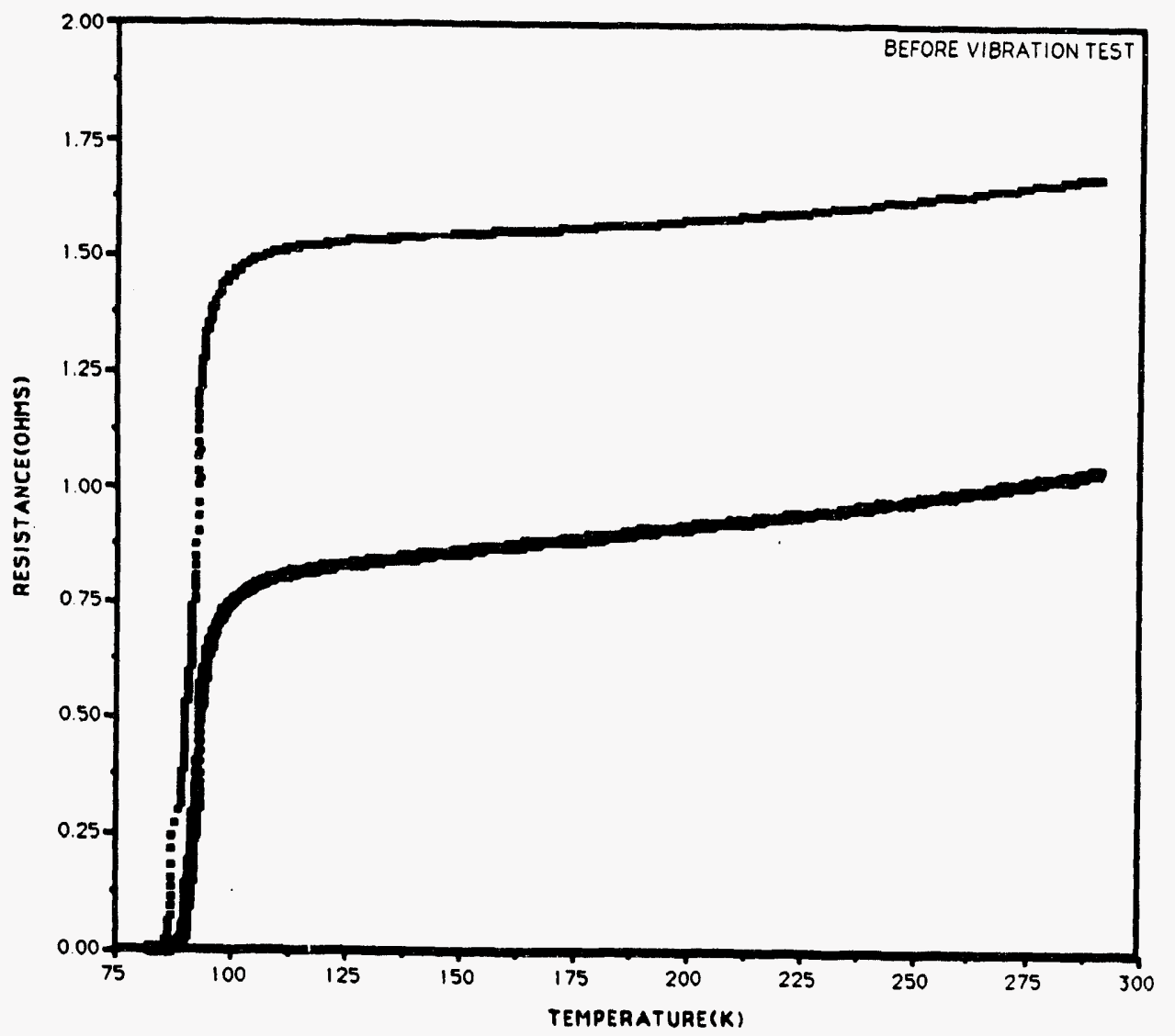

Figure 2. Sample 366 and 367 Resistance vs. Temperature before Vibration

5

M911206N1 


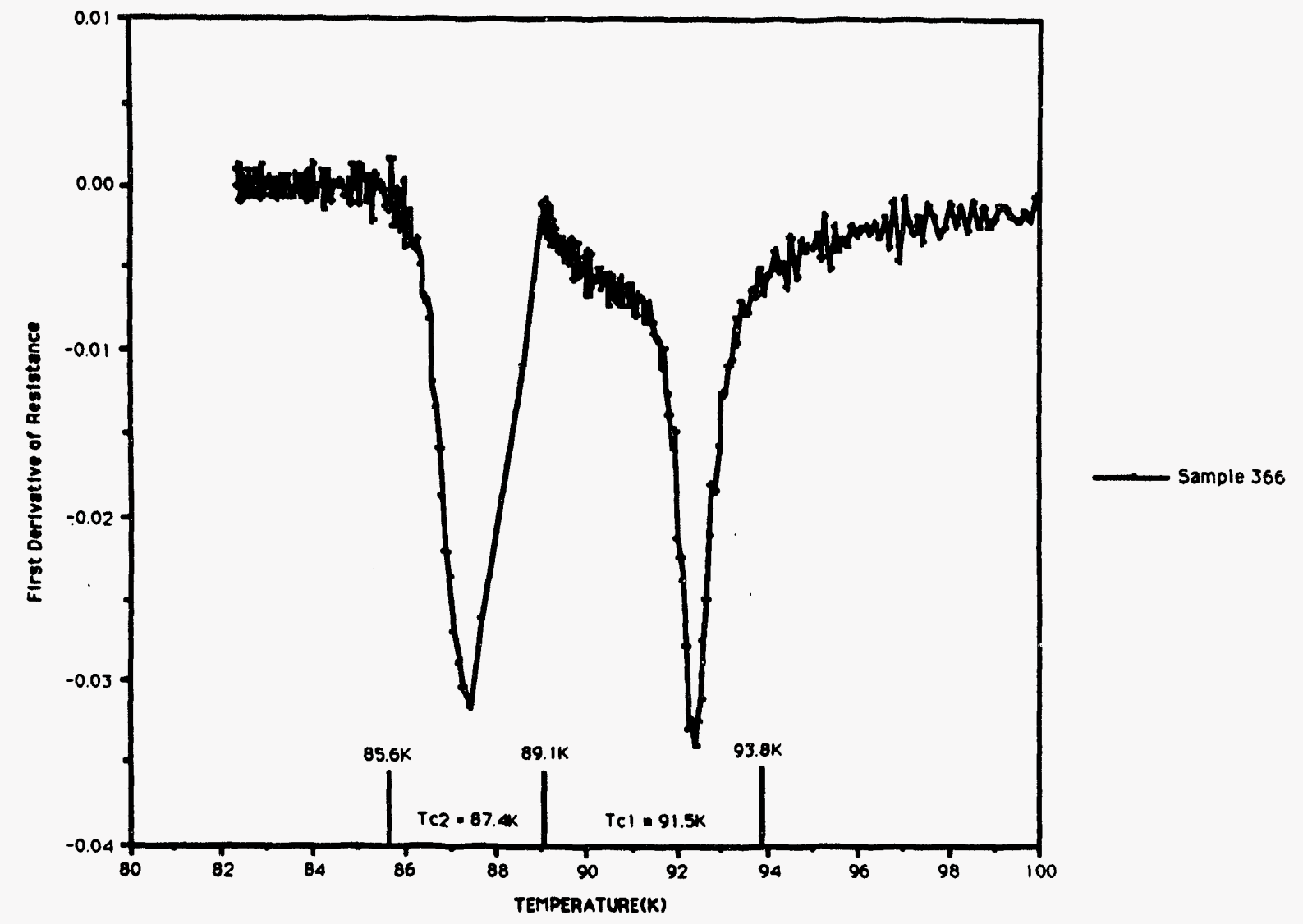

Figure 3. Typical Derivative of Resistance vs. Temperature Curve 


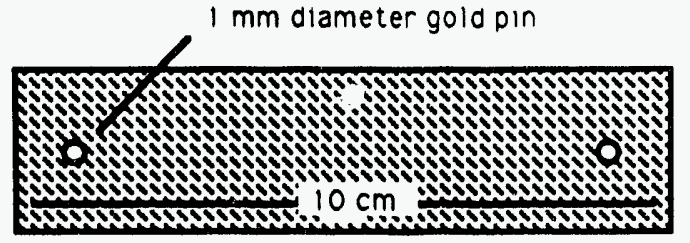

Side view of sample on vibration table (motion is in and out of page)

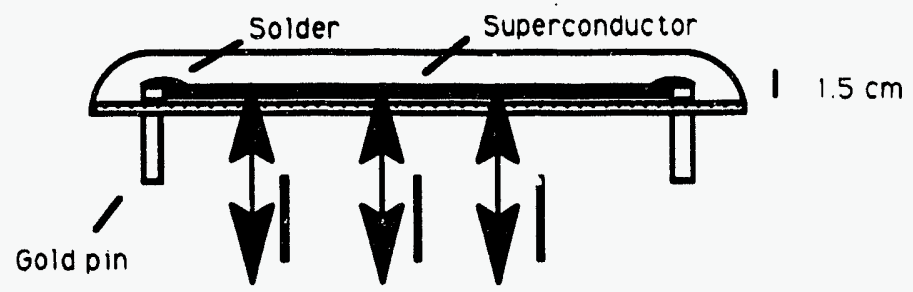

Top view of sample on vibration table (each end of the sample was fixed to the table)

Figure 4. Configuration of the Sample on the Vibration Table 


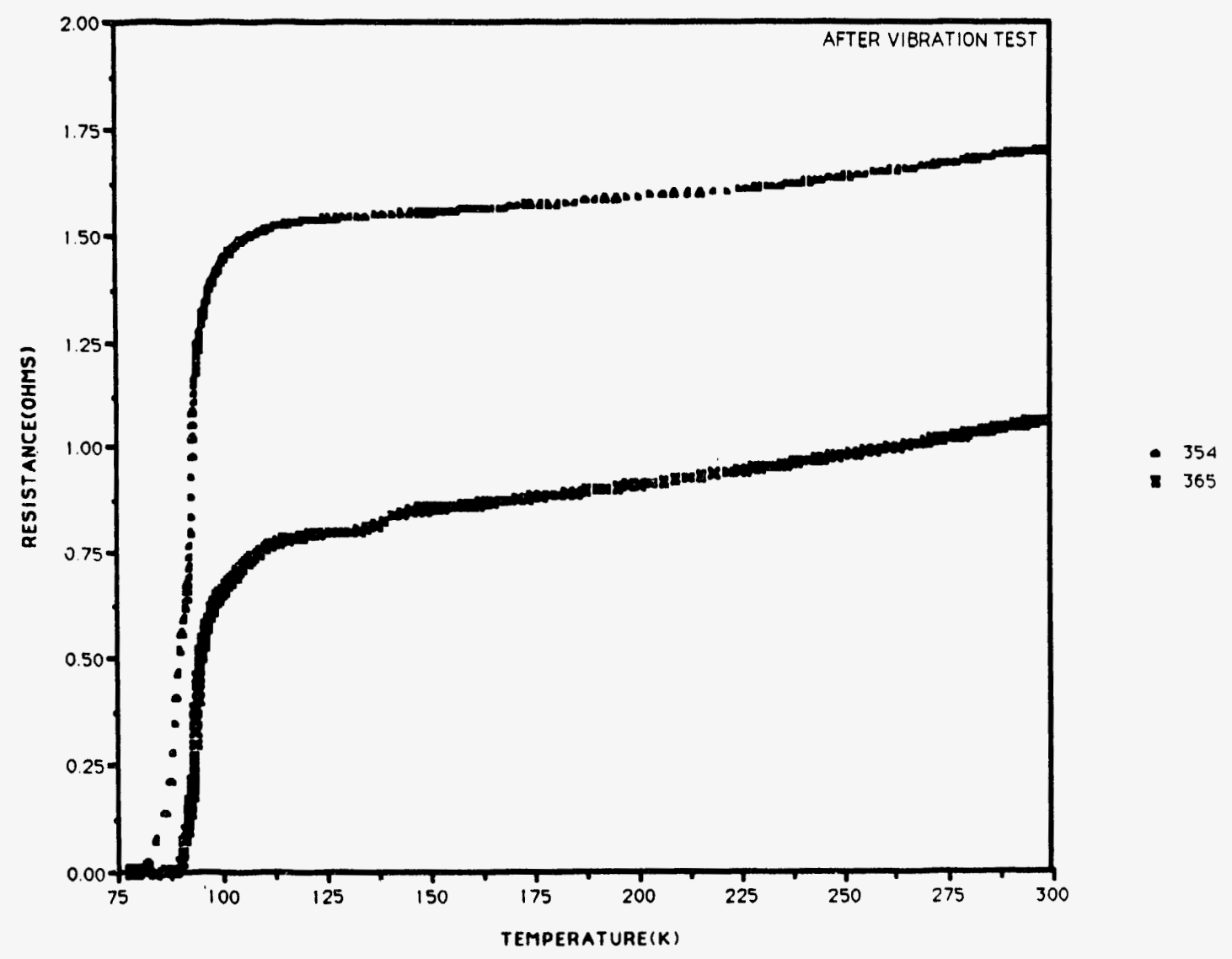

Figure 5. Sample 364 and 365 Resistance vs. Temperature Curves after Vibration 


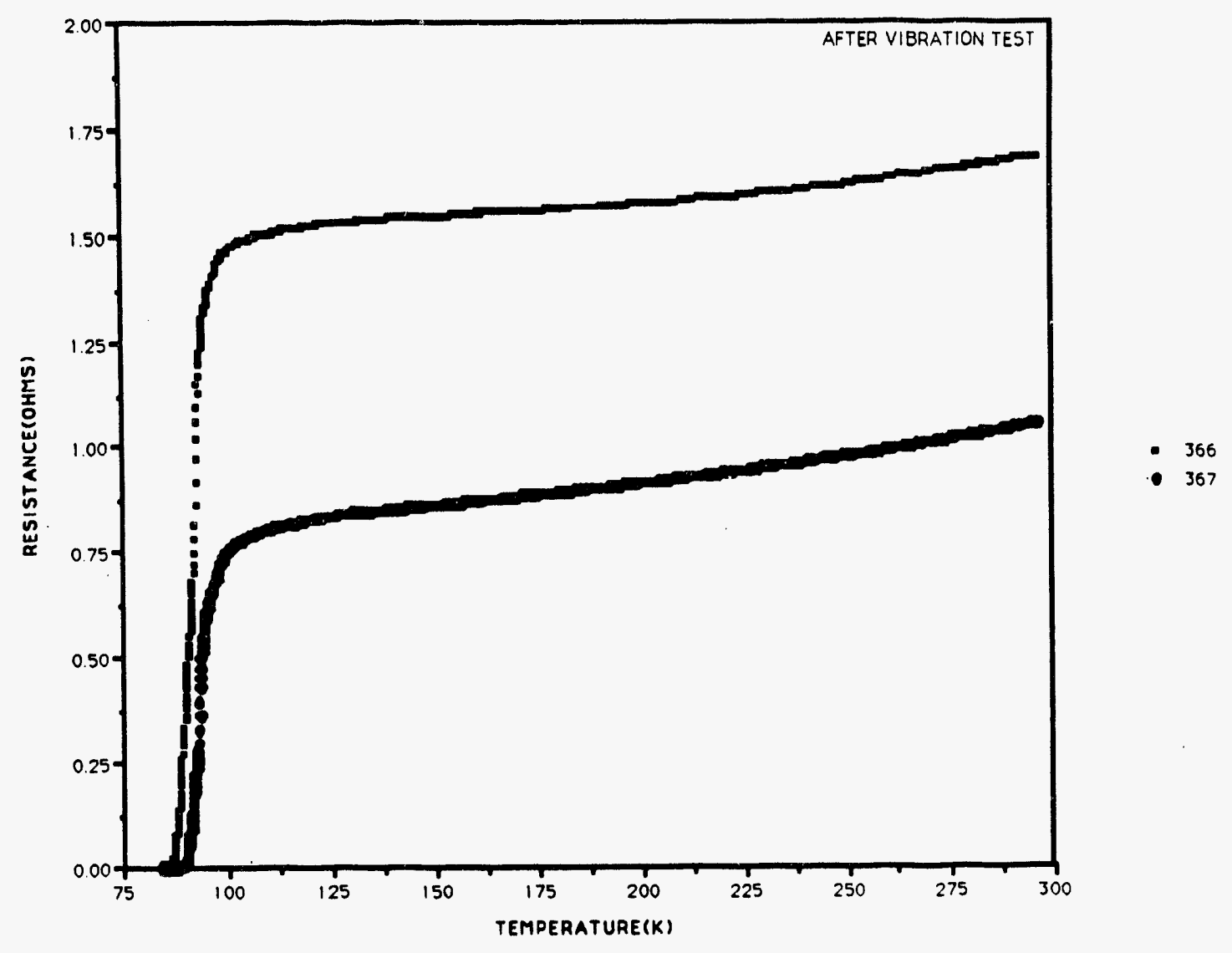

Figure 6. Sample 366 and 367 Resistance vs. Temperature Curves after Vibration 


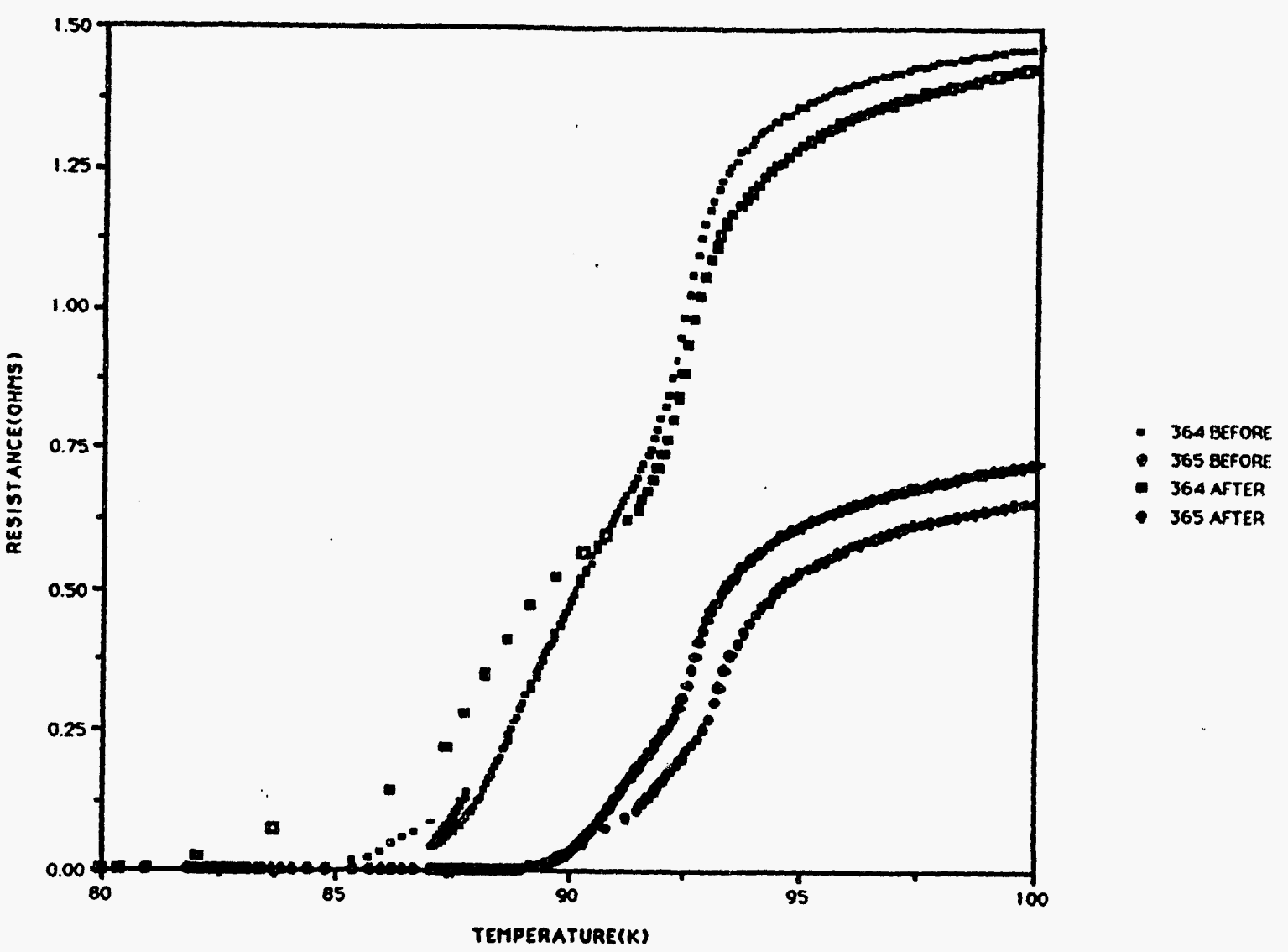

Figure 7. Comparison of Samples 364 and 365 before and after Vibration 


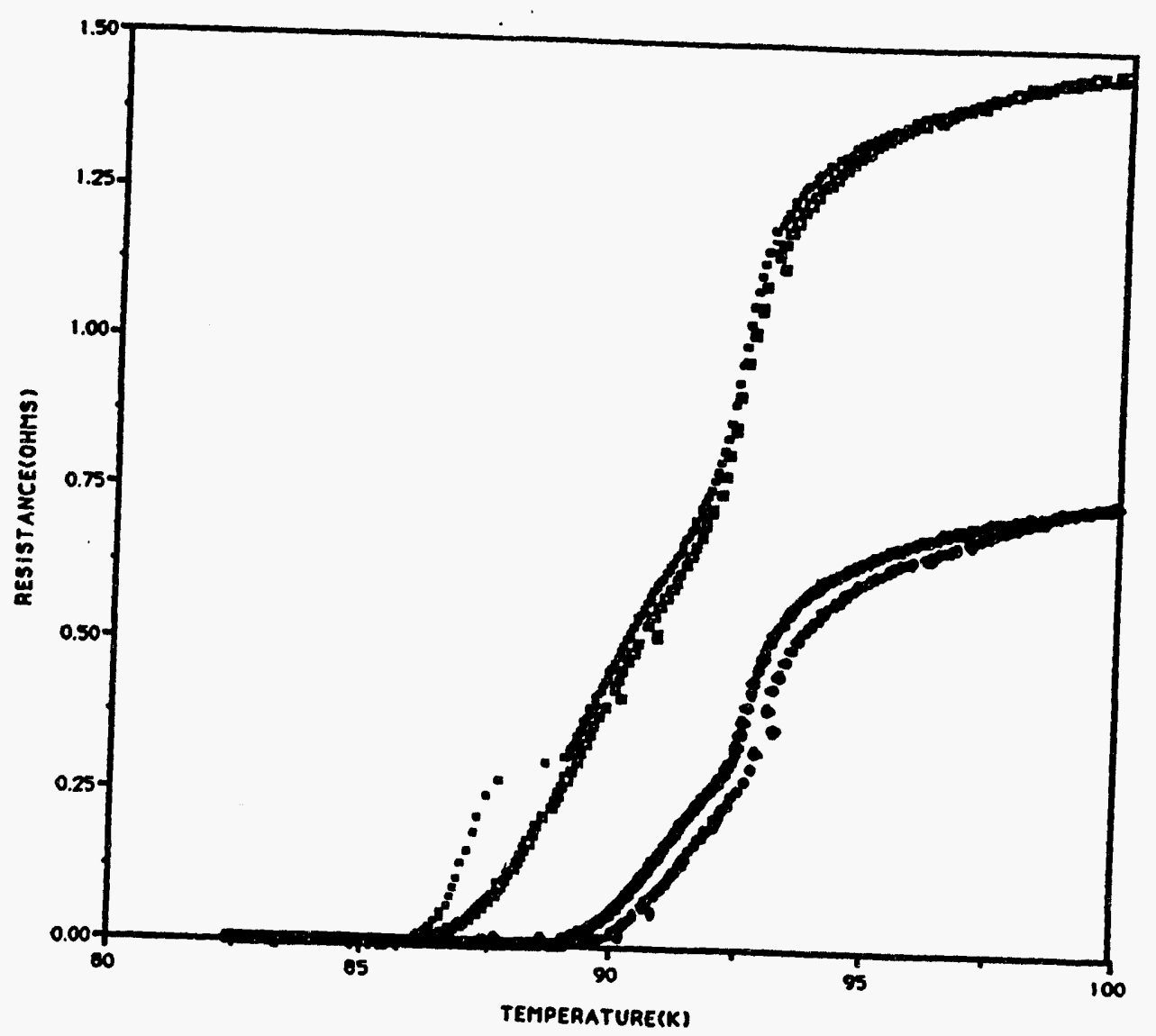

- 366 BEFORE

- 367 BEFORE

- 366 after

- 367 after

Figure 8. Comparison of Samples 366 and 367 before and after Vibration

12

nastrossi 


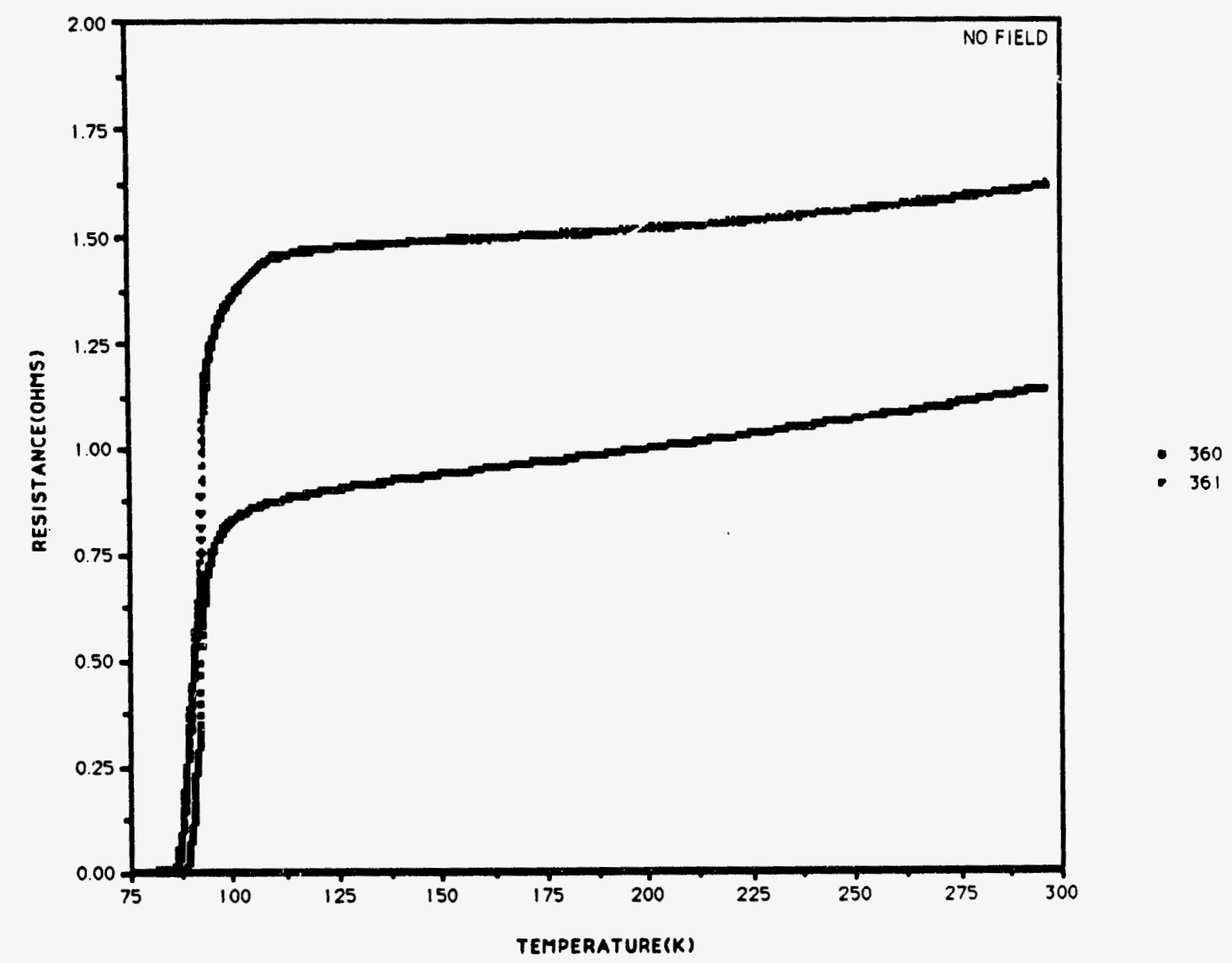

Figure 9. Zero Field Resistance vs. Temperature Curves for Samples 360 and 361 


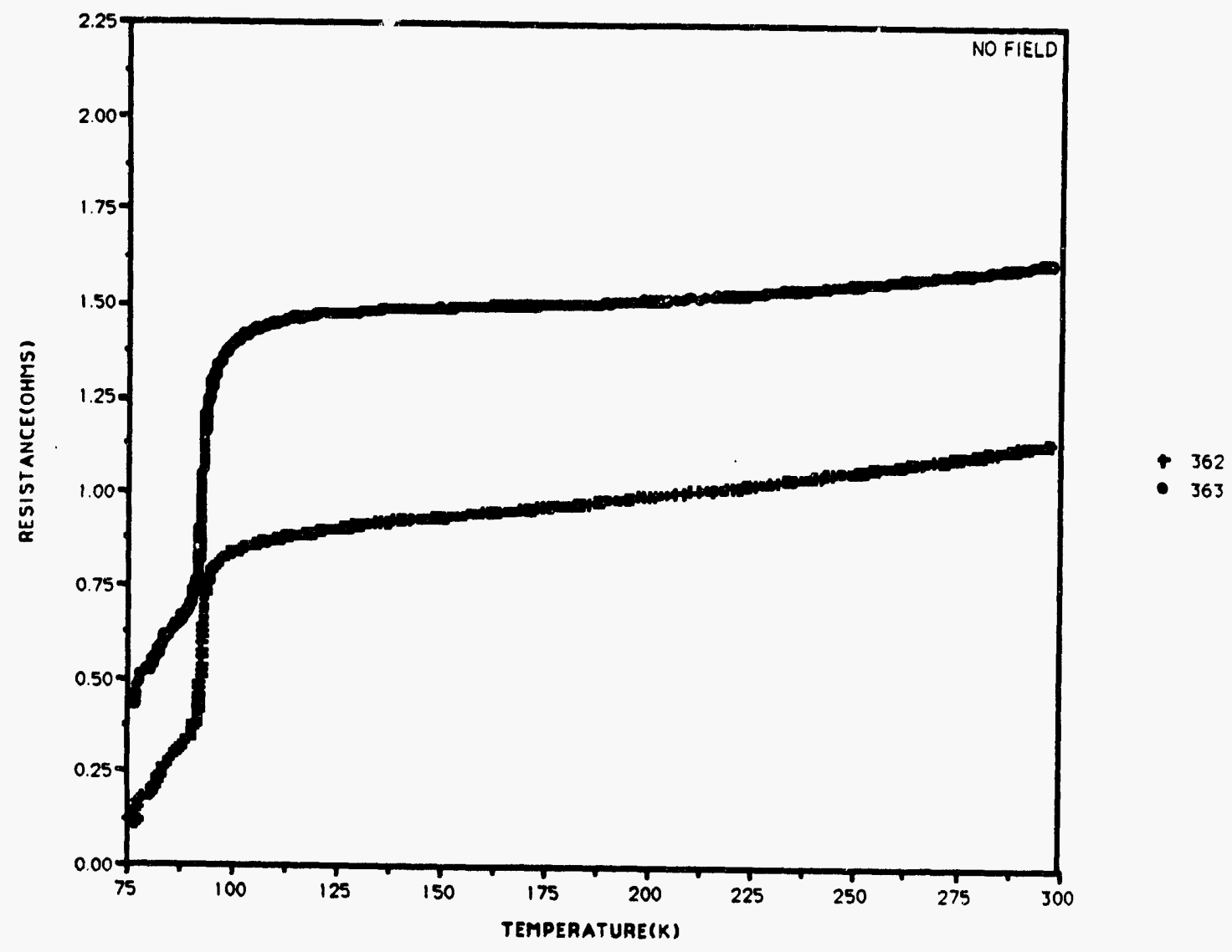

Figure 10. Zero Field Resistance vs. Temperature Curves for Samples 362 and 363 


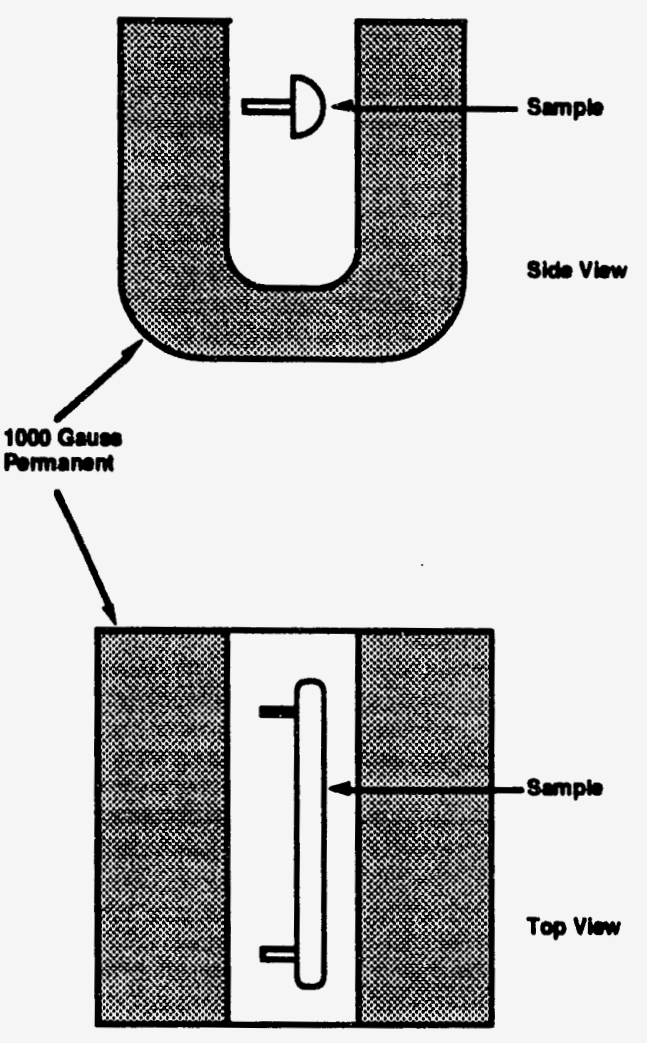

Figure 11. Schematic of Sample Surrounded by Permanent Magnet 


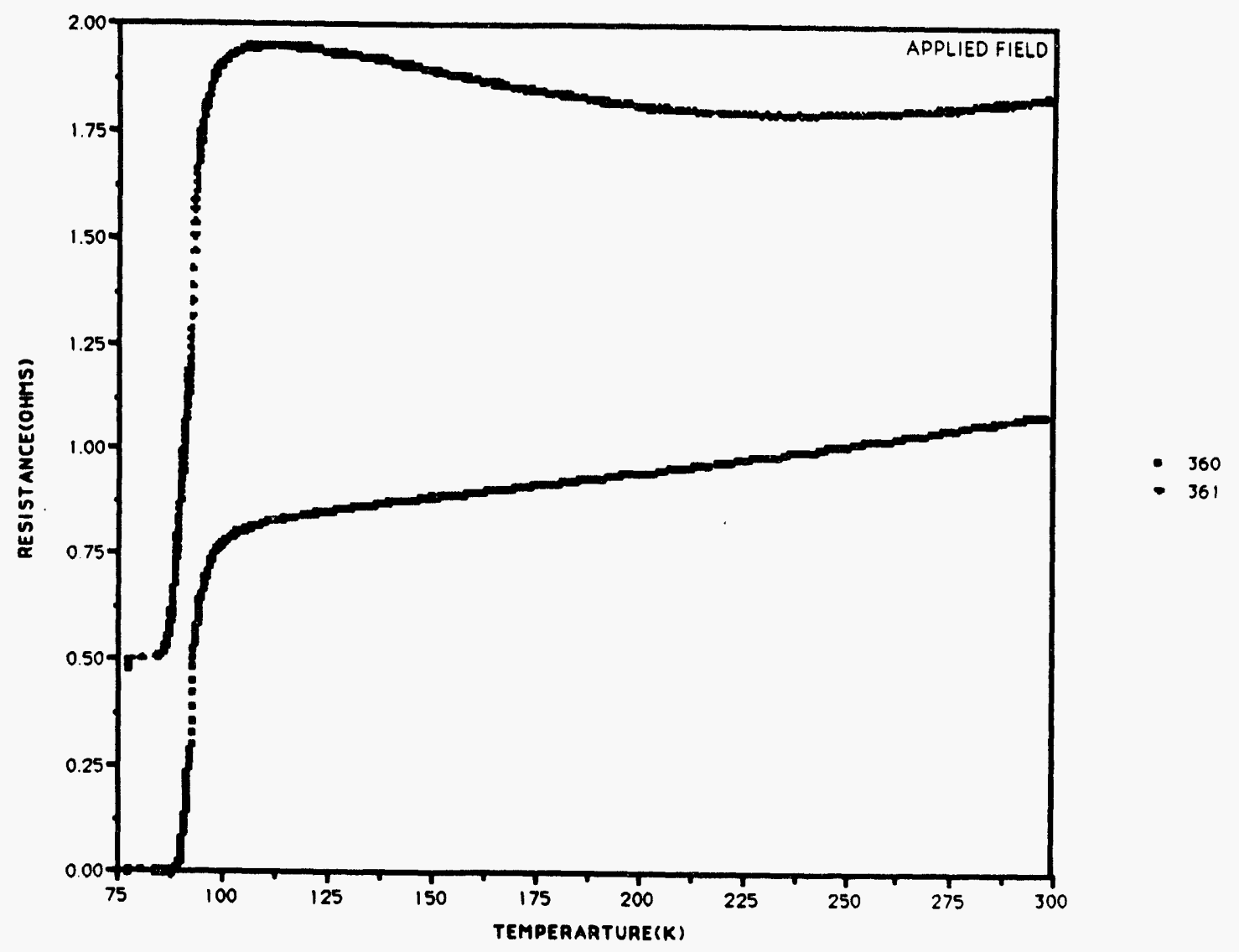

Figure 12. 1000 Gauss Field Resistance vs. Temperature Curves for Samples 360 and 361 


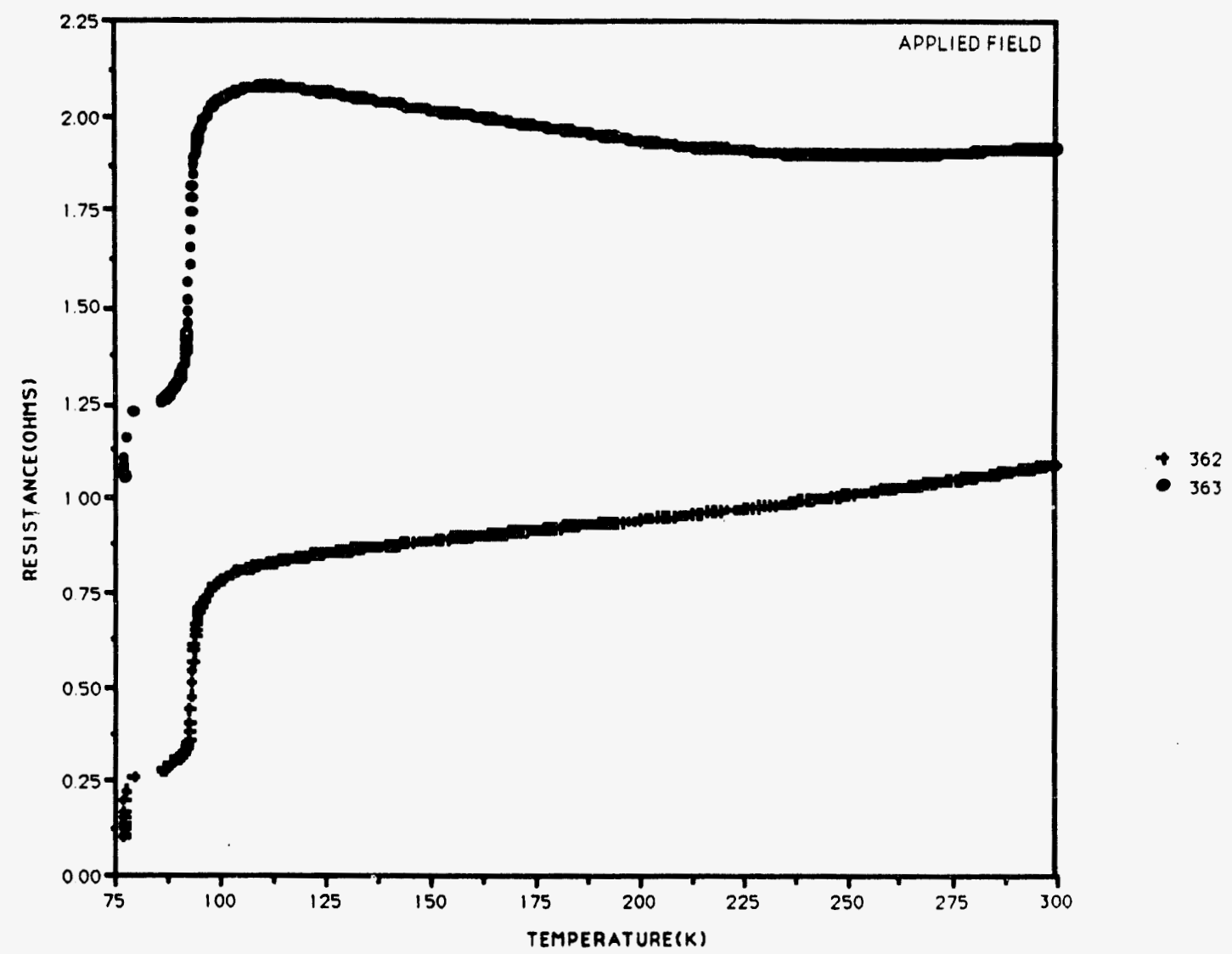

Figure 13. 1000 Gauss Field Resistance vs. Temperature Curves for Samples 362 and 363 


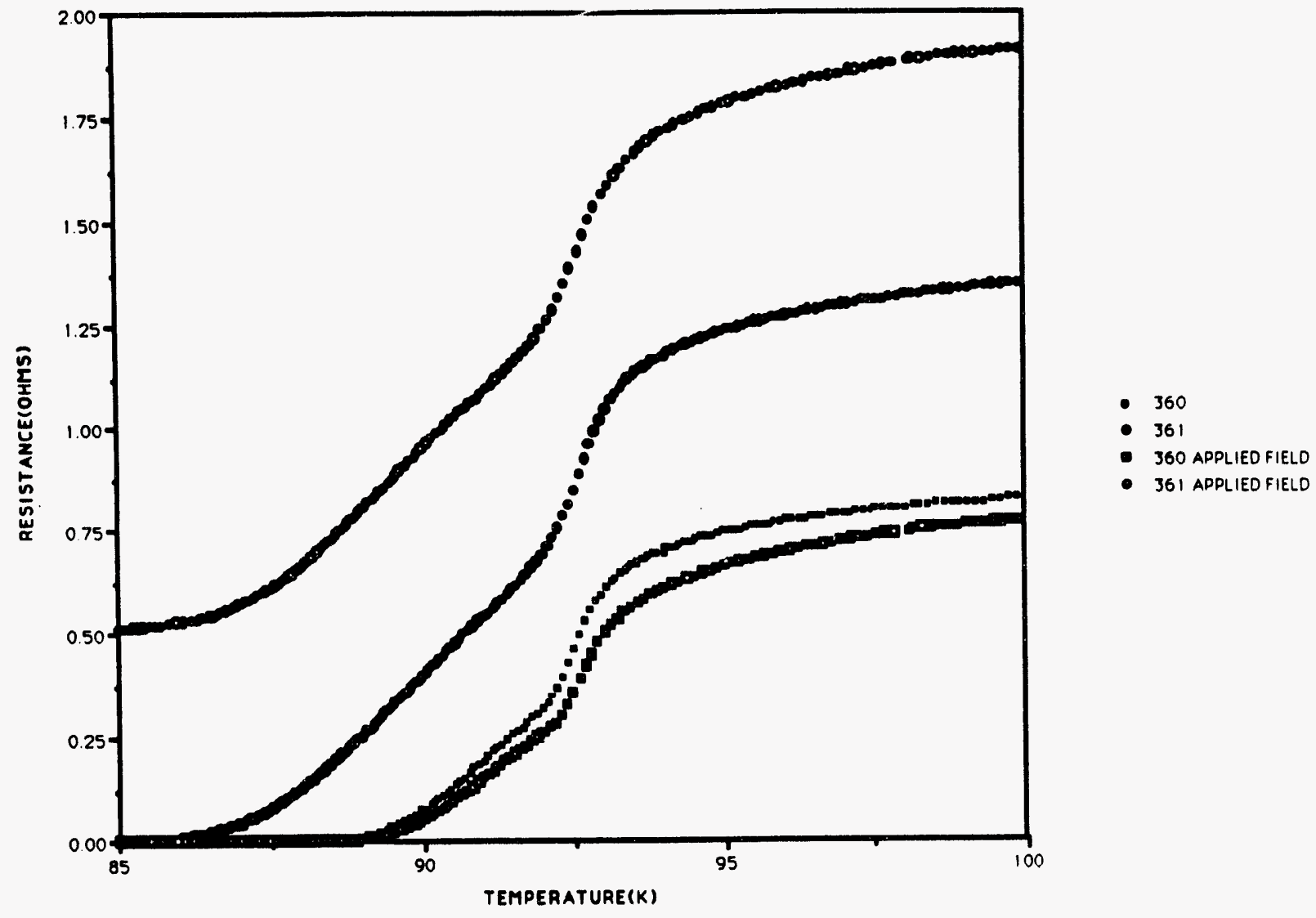

Figure 14. Comparison of Samples 360 and 361 with and without a Magnetic Field 


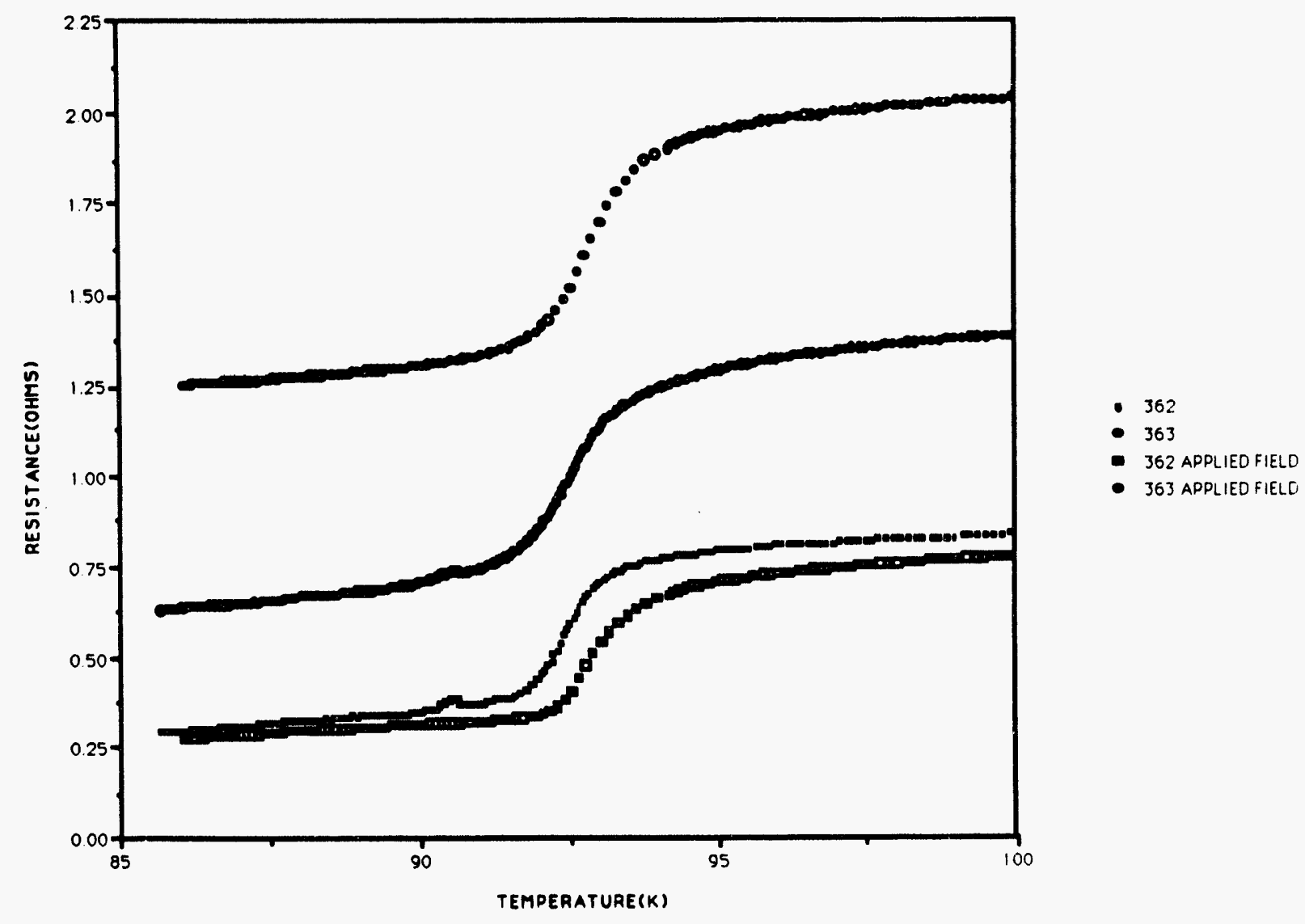

Figure 15. Comparison of Samples 362 and 363 with and without a Magnetic Field 


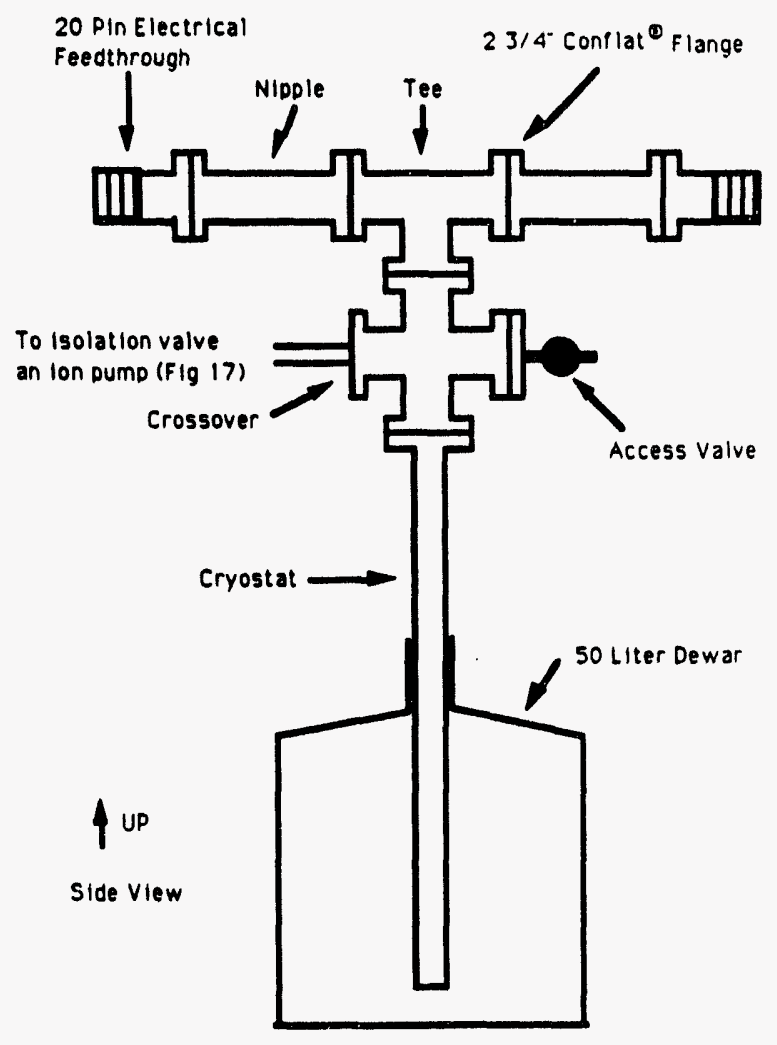

Electrical feedthroughs

Figure 16. Vacuum System Chamber with Cryostat and Electrical Feodthroughs 



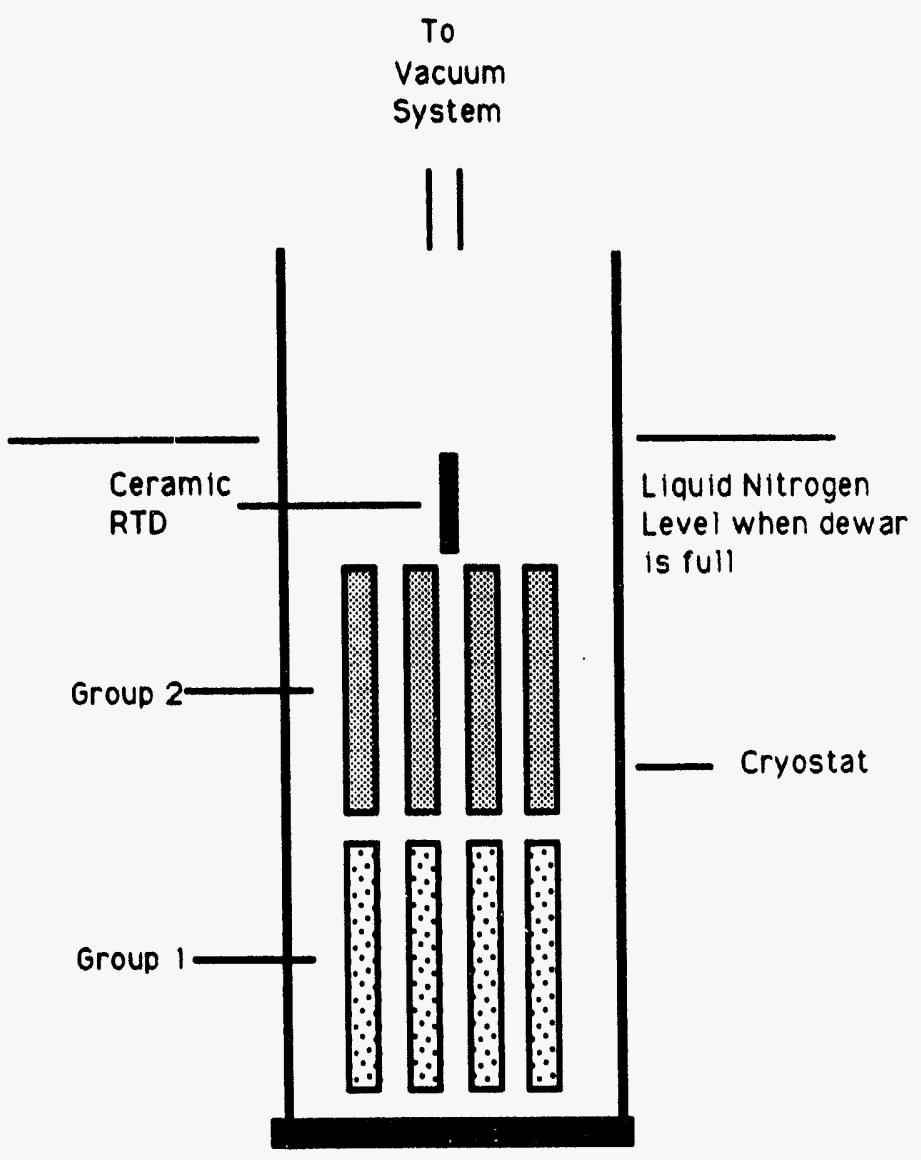

Figure 18. Schematic Orientation of Samples in Cryostat 

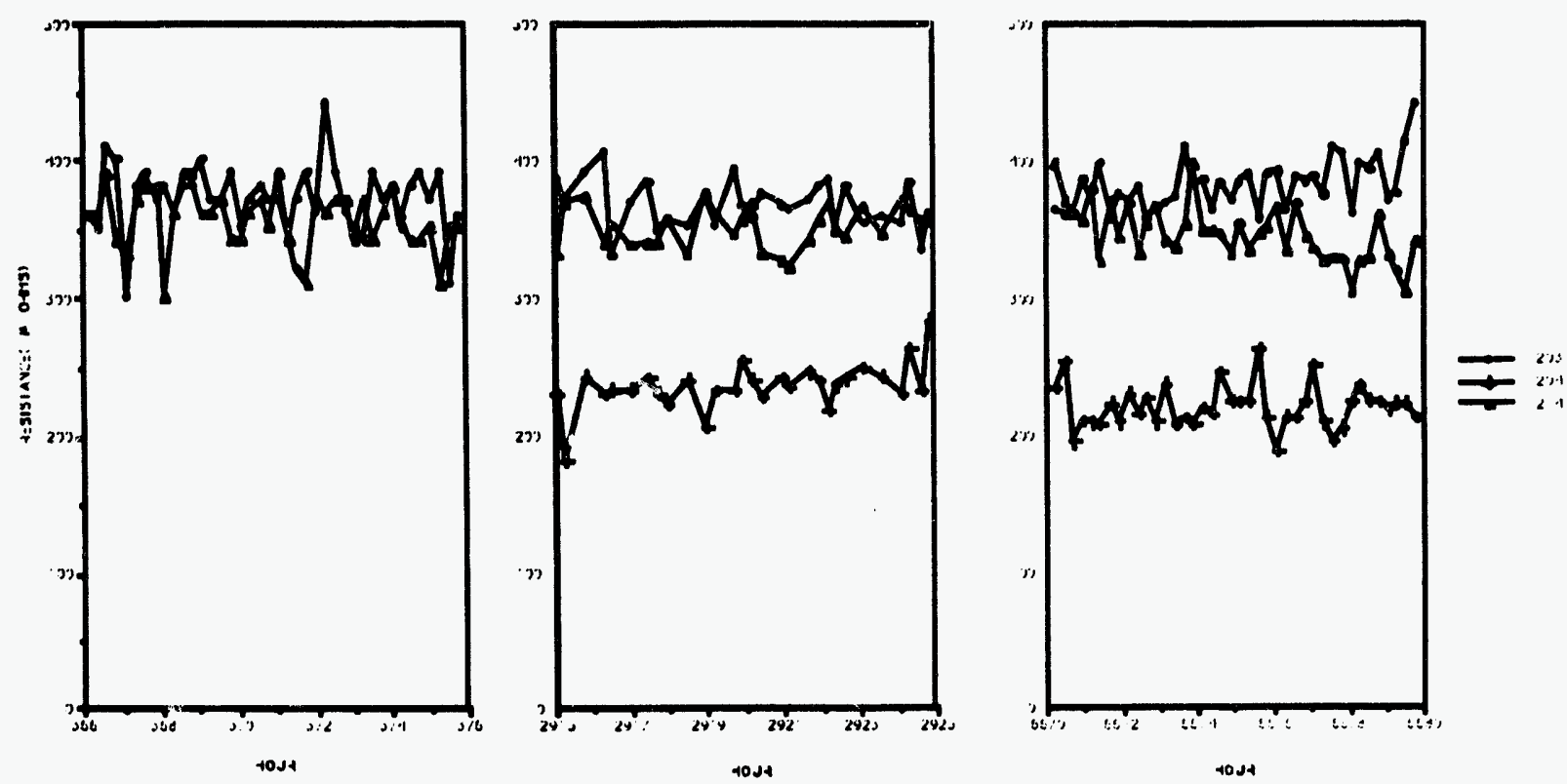

Figure 19. Resistance Data for Samples 203, 204, and 214 over 6700 hours 


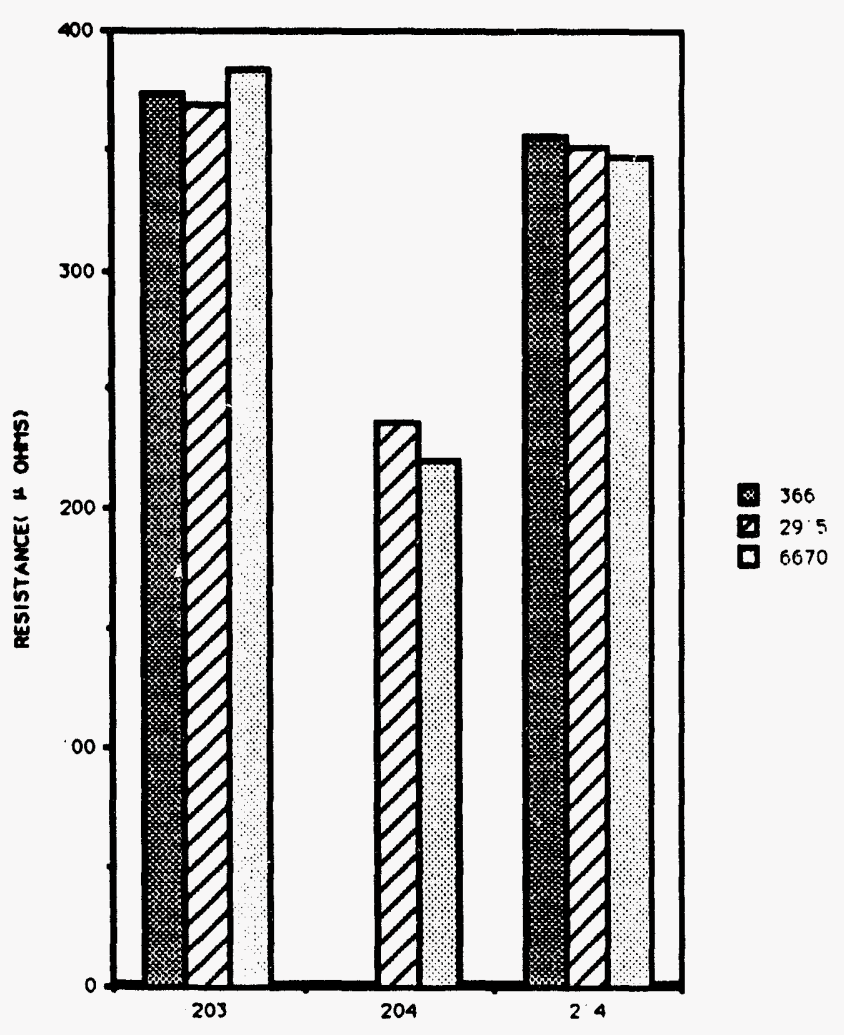

Figure 20. Average Resistance for each Data Segment for Samples 203, 204, and 214 

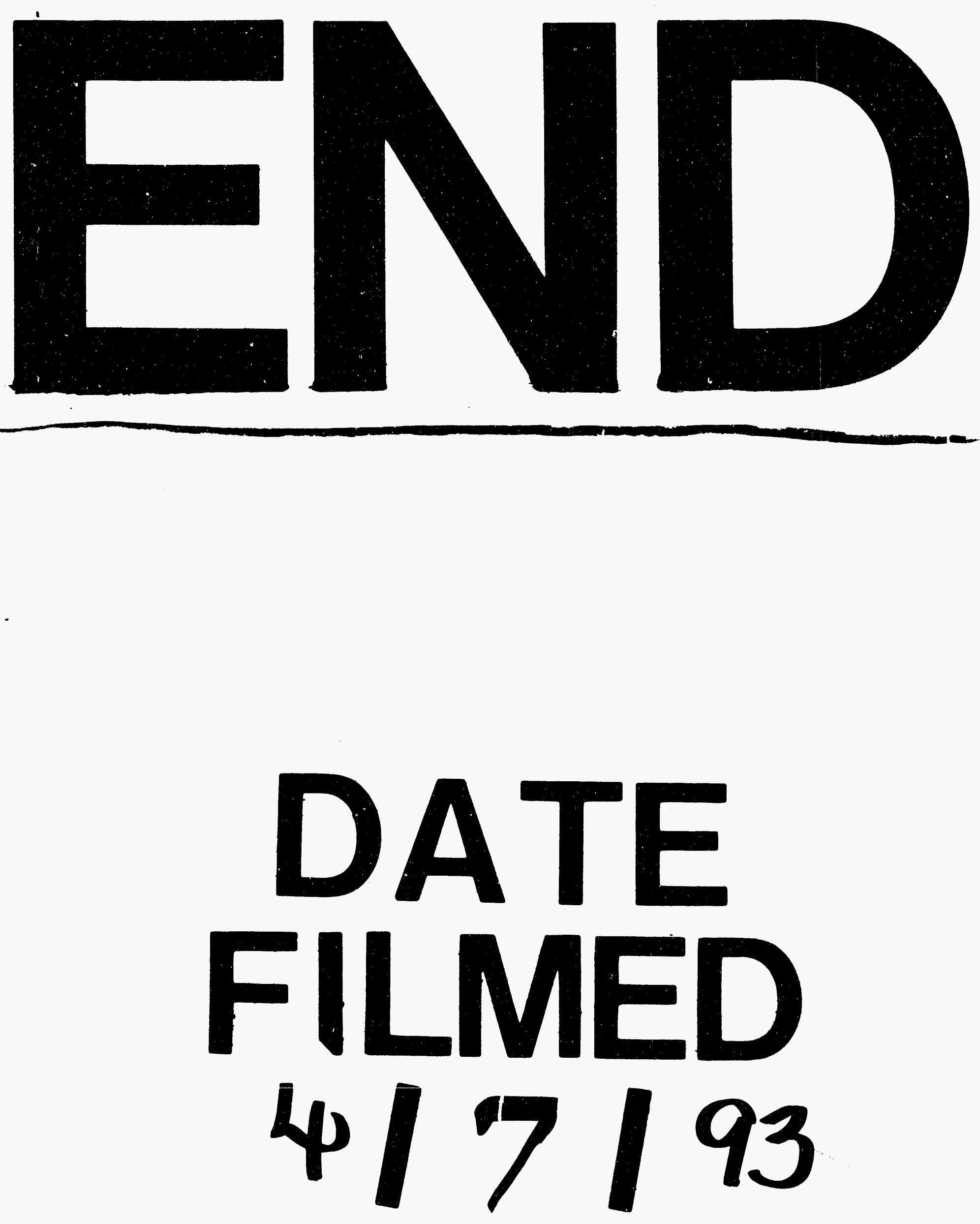
